\title{
2 Land Use Differences Across Socioeconomic Boundaries and Implications for Air Quality
}

\author{
Daniel L. Mendoza 1,2* \\ 1 Department of City \& Metropolitan Planning, University of Utah, Salt Lake City, UT 84112, USA \\ 2 Department of Atmospheric Sciences, University of Utah, Salt Lake City, UT 84112, USA \\ * Correspondence: daniel.mendoza@utah.edu
}

Received: date; Accepted: date; Published: date

\begin{abstract}
Multiple social and environmental justice concerns are linked to urban form such as the distribution of socioeconomic class populations, healthcare spending, air pollution exposure, and human mobility. This study used $1 \mathrm{~m}$ resolved LIDAR data to characterize land use in Salt Lake County, Utah and associate it with sociodemographic and air quality data at the census block group and zip code levels. We found that increasing tree cover was associated with higher per capita income and lower minority populations while increasing built cover was linked to lower per capita income and higher minority populations. Air quality showed less strong correlations, however, decreased non irrigated cover, increased built cover, and higher amounts of households living under poverty was related to higher long-term $\mathrm{PM}_{2.5}$ exposure. Several policy efforts have been undertaken to improve air quality and reduce negative health outcomes in Utah which are being informed by regulatory and research grade air quality sensors.
\end{abstract}

Keywords: Land Cover; LIDAR; Sociodemographics; Built Environment; Urban Form; Air Quality; Social Justice; Environmental Justice; Policy; Localized Action.

\section{Introduction}

Land cover at the urban level has often been studied using LIDAR data due to its thoroughness and availability [1-2]. The urban form influences behavior ranging from transit use [3] to how children go to school [4]. Increased tree cover has been shown to promote healthier communities with highly-built areas showing the opposite effect [5-7]. As cities continue to increase in spatial extent and population, there is growing need to better characterize urban emissions, particularly of criteria air pollutants (CAPs) for metropolitan planning [8-9], health [10], and emissions reduction purposes, from global to local scales [11-12].

Multiple social and environmental justice concerns are linked to urban form such as the distribution of socioeconomic class populations [13], healthcare spending [14], and human mobility [15]. Urban areas composed of lower socioeconomic populations are disproportionately affected by hotter temperatures [16] which has been shown to have adverse health impacts [17-19]. Furthermore, land cover disparities have been associated with air pollution [20] and several health outcomes [21] including asthma hospitalizations [22].

In the present study we combine a $1 \mathrm{~m}$ land cover dataset with sociodemographic variables and air quality measurements to show their linkages. This analysis, performed at the census block group and zip code level, facilitates localized policy actions by identifying areas of concern at fine resolution. This is the first use of this highly resolved data for Salt Lake County and will set a precedent for future land cover analyses.

\section{Materials and Methods}

\subsection{Land Use Data}


Five land cover classes were mapped for the urban extent of the Salt Lake Valley (approximately $840 \mathrm{~km}^{2}$ ) using two high spatial resolution datasets. Four-band, $1 \mathrm{~m}$ resolution orthoimagery was collected under the National Agriculture Imagery Program (NAIP) in summer 2014. Orthoimage brightness values were used to calculate normalized difference vegetation index [23], green-red vegetation index [24-25], and metrics of spatial variability of each band and index. First return, last return, and bare earth digital surface models derived from lidar data collected in late 2013 and early 2014 were resampled from their original $0.5 \mathrm{~m}$ resolution to match the $1 \mathrm{~m}$ resolution of the orthoimagery. The surface models were differenced, and metrics of spatial variability were also calculated. Orthoimage and lidar variables were extracted from polygons for deciduous tree, coniferous tree, irrigated low-stature vegetation, non-irrigated vegetation/soil, and impervious surface/water classes, and then used to train a random forests classifier [26]. Classification results were assessed using an independent set of polygons and yielded an overall accuracy of $96.2 \%$ and a 0.94 kappa value [27]. The land cover categories are listed in Table 1.

Table 1. Salt Lake County 1m LIDAR Land Cover Data Categories.

\begin{tabular}{|c|c|}
\hline Land Cover Value & Land Cover Category \\
\hline 1 & Coniferous Tree \\
\hline 2 & Deciduous Tree \\
\hline 3 & Low stature irrigated vegetation (grass, low shrubs) \\
\hline 4 & Low impervious surface (roads, driveways, parking lots, etc.) \\
\hline 5 & Roof \\
\hline 6 & Low stature non-irrigated vegetation and soil \\
\hline 7 & Water \\
\hline
\end{tabular}

\subsection{Sociodemographic Data}

Zip code level sociodemographic data was retrieved from the Healthy Salt Lake dataset [28] and census block group data was obtained from the United State Census Bureau American Community Survey [29]. The relevant data fields extracted were: Percent Minority Population, Per Capita Income, and Percentage of Households Living Below Poverty. The shapefiles for each dataset provided centroid latitude and longitude coordinates. Salt Lake County has 612 block groups and 34 zip codes were used in this analysis.

\subsection{Air Pollution Data}

Salt Lake County area is home to a dense criteria air pollution observational network facilitating a wide range of observation studies [30-32]. We used data from the Utah Division of Air Quality (UDAQ) regulatory observational network, and the University of Utah (UofU) stationary and mobile platform network. The mobile network consists of air quality sensors that measure fine particulate matter (PM2.5) and ozone [33-34] mounted on top of electric Utah Transit Authority (UTA) light-rail trains. We estimated mean PM2.5 concentrations for three years (2017-2019) at each zip code's centroid using the inverse distance square weighting (IDW) method [35-36].

\subsection{Geographical and Sociodemographic Comparisons}

The $1 \mathrm{~m}$ land use cover data was intersected with the zip code and block group shapefiles to calculate areal land cover by category using QGIS version 3.14.15. These values were converted to percent land cover at each geographical resolution. In this study, Coniferous and Deciduous Trees were combined to form the "Tree" category. Similarly, Low impervious surface and Roof were combined into the "Built" category.

\section{Results}


Salt Lake County has a marked East-West sociodemographic divide demarcated by U.S. Interstate 15 which runs North-South. The West Side is developing at a rapid pace and is home to a higher percent minority and lower income population. The land cover implications of these differences are shown in Figure 1. Figure 1.a clearly demonstrates the longitudinal distribution of tree cover, with the older and wealthier East Side home to more trees. The built cover (Figure 1.b) is highest in the central part of the county as this is the commercial and industrial center along Interstate 15. The built cover drops rapidly on the East Side and is comparatively higher on the West Side due to the siting of factories and commercial buildings in that part of the county. The distribution of water is relatively constant with the exception of the Jordan River which runs near to the center of the county (Figure 1.c). Lastly, irrigated cover is highly concentrated in the central part of the county as it generally belongs to commercial and institutional buildings, as well as homes, and is less present on the East Side.

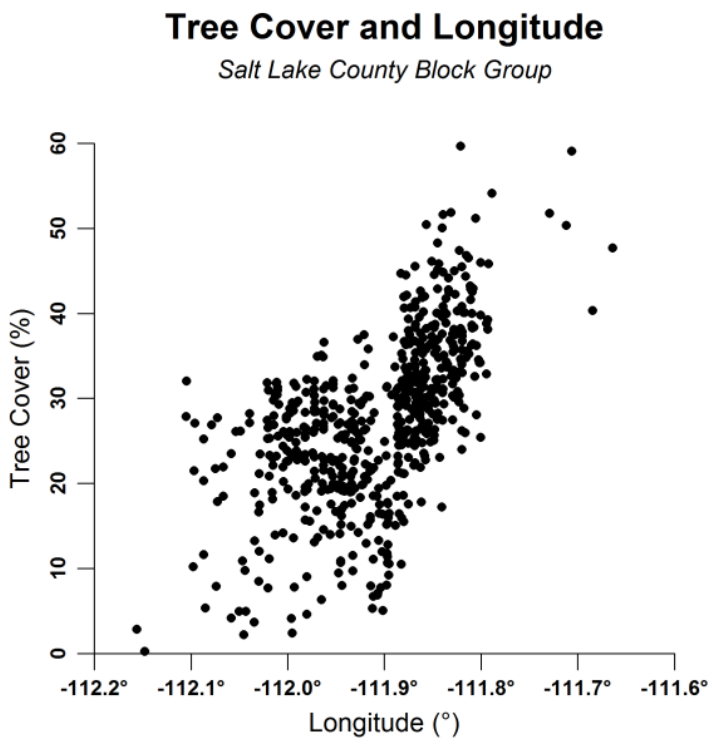

(a)

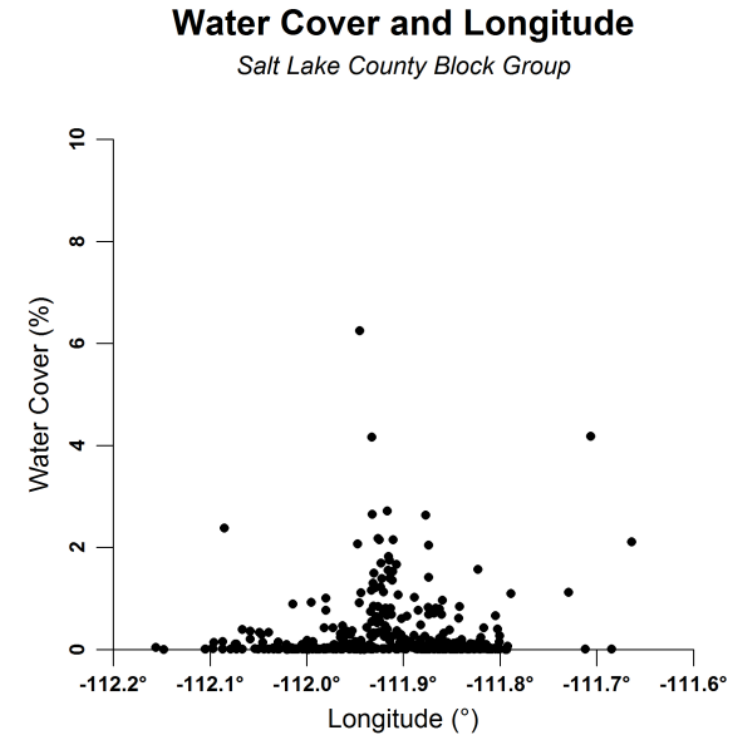

(c)

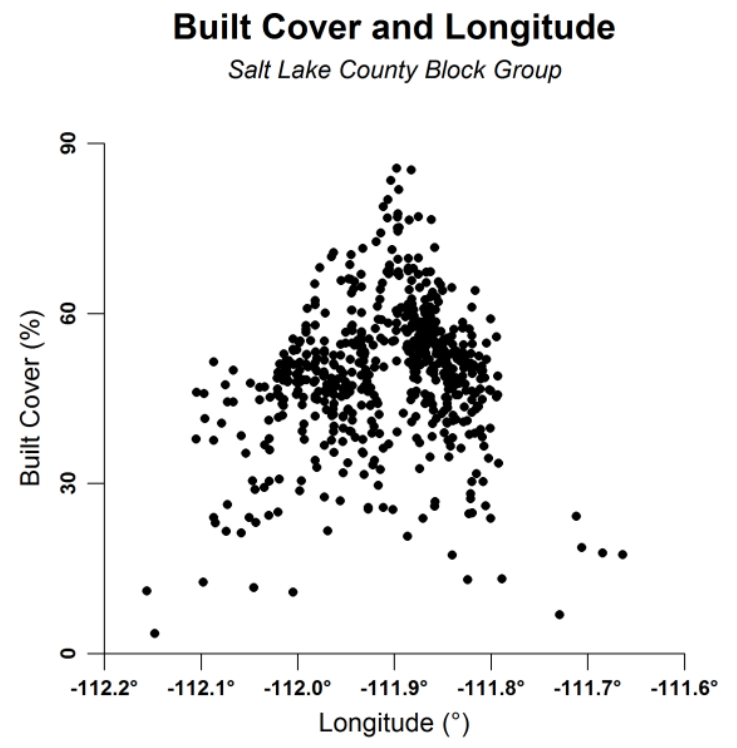

(b)

Irrigated Cover and Longitude Salt Lake County Block Group

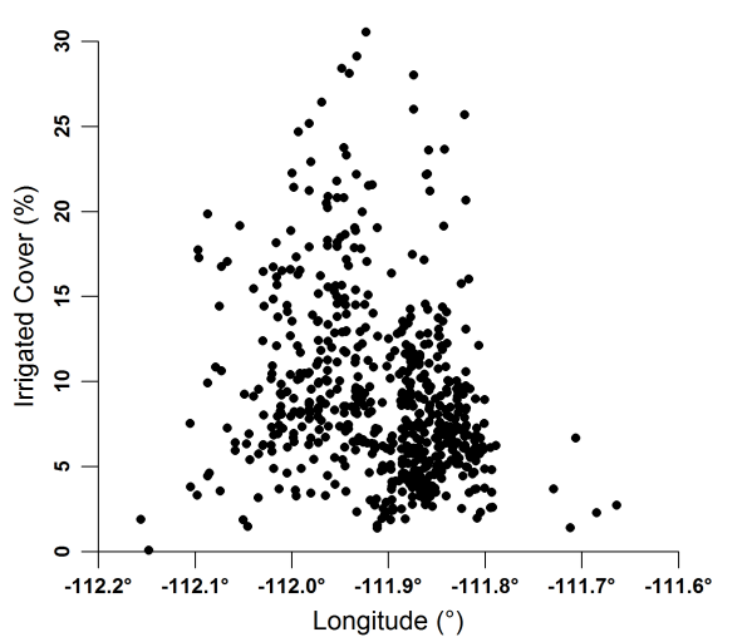

(d)

Figure 1. Longitudinal distribution of various land cover categories at the block group level: (a) Trees; (b) Built; (c) Water; and (d) Irrigated. 
Figure 2 shows relationships between sociodemographic variables and land cover. Tree cover increases with increasing per capita income at the census block group as seen in Figure 2.a., however, it decreases with increasing minority population (Figure 2.b). The built environment displays the opposite pattern with decreasing cover associated with higher per capita income (Figure 2.c) and increasing cover related with higher minority population (Figure 2.d).

Tree Cover and Per Capita Income Salt Lake County Block Group

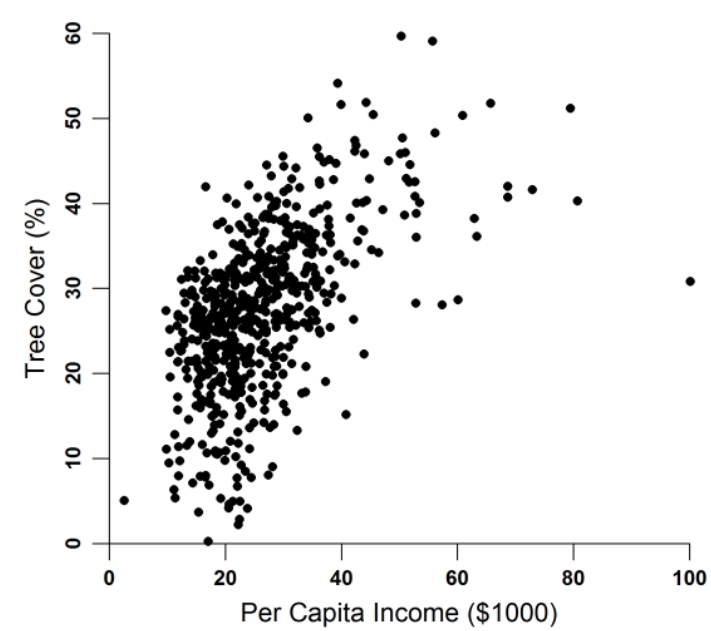

(a)

Built Cover and Per Capita Income Salt Lake County Block Group

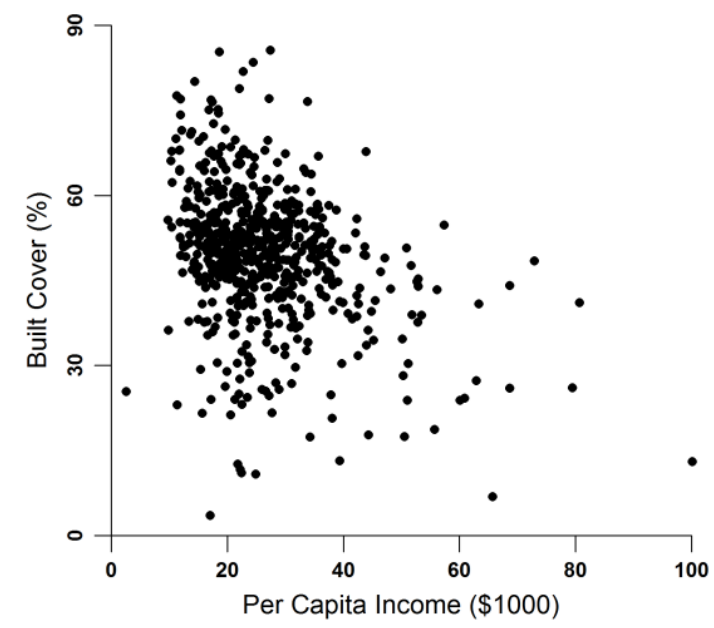

(C)

\section{Tree Cover and Minority Population} Salt Lake County Block Group

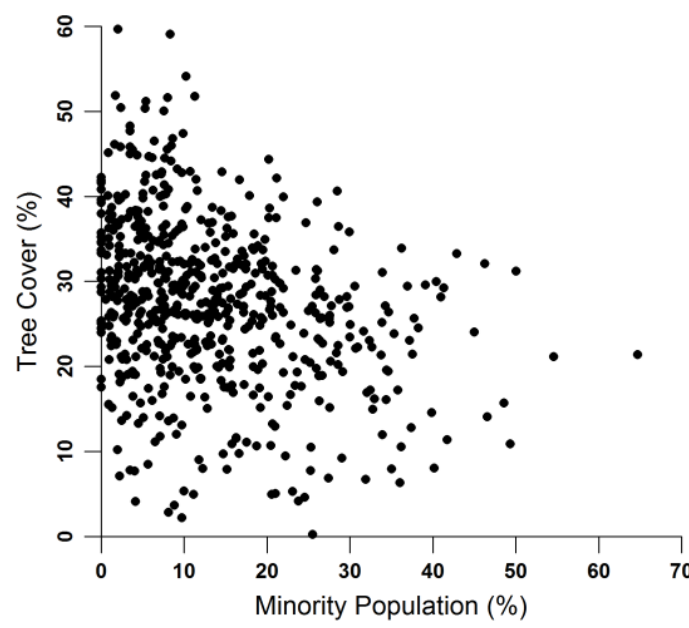

(b)

Built Cover and Minority Population Salt Lake County Block Group

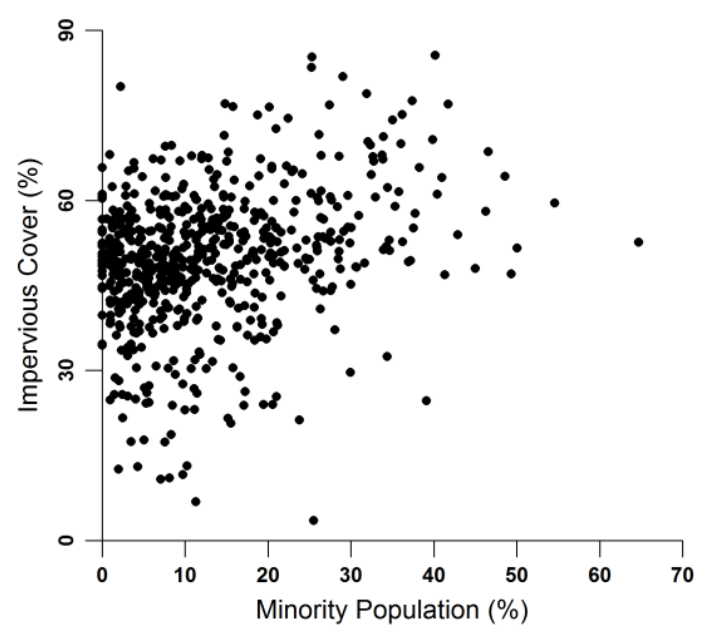

(d)

Figure 2. Sociodemographic distribution of various land cover categories at the block group level: (a) Tree cover and per capita income; (b) Tree cover and minority population; (c) Built cover and per capita income; and (d) Built cover and minority population.

\subsection{Long Term PM2.5 Concentrations and Land Cover and Household Poverty}

The relationships between fine particulate matter concentrations at zip code centroids and study variables are shown in Figure 3. Higher long-term pollutant concentrations are associated with increasing built cover (Figure 3.a) and lower concentrations are linked with increasing non irrigated cover (Figure 3.b). There is no clearly visible relationship between $\mathrm{PM}_{2.5}$ concentrations and tree cover (Figure 3.c). A comparatively weaker association between increased pollutant concentrations and percent of households living below poverty is shown in Figure 3.d. 
Annual $\mathrm{PM}_{2.5}$ and Built Cover

Salt Lake County Zip Code

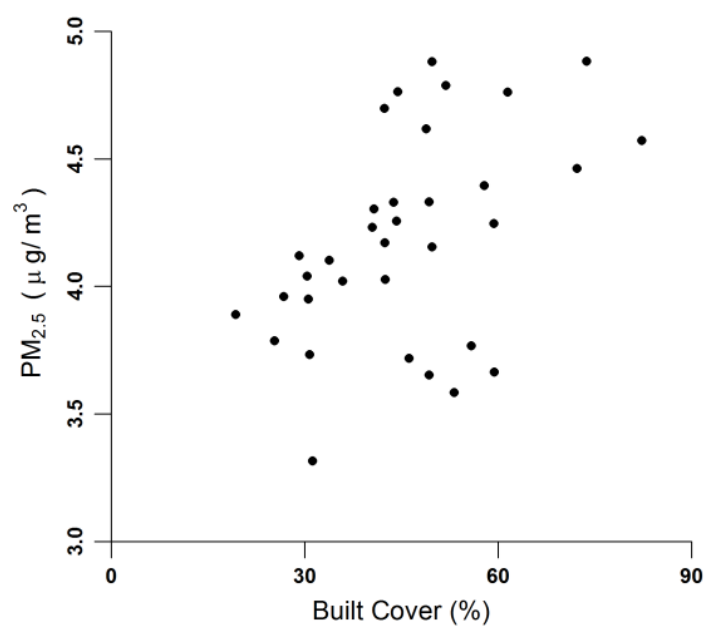

(a)

Annual $\mathbf{P M}_{2.5}$ and Tree Cover Salt Lake County Zip Code

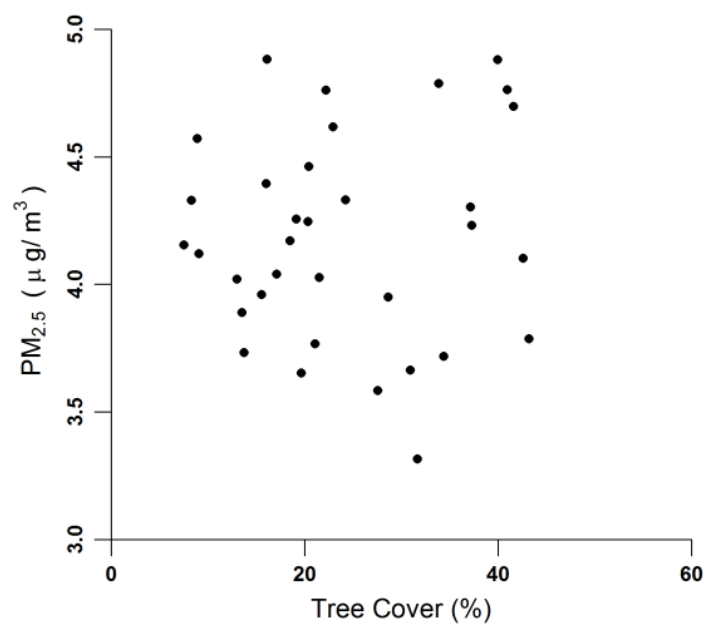

(c)

\section{Annual $\mathbf{P M}_{2.5}$ and Non Irrigated Cover}

Salt Lake County Zip Code

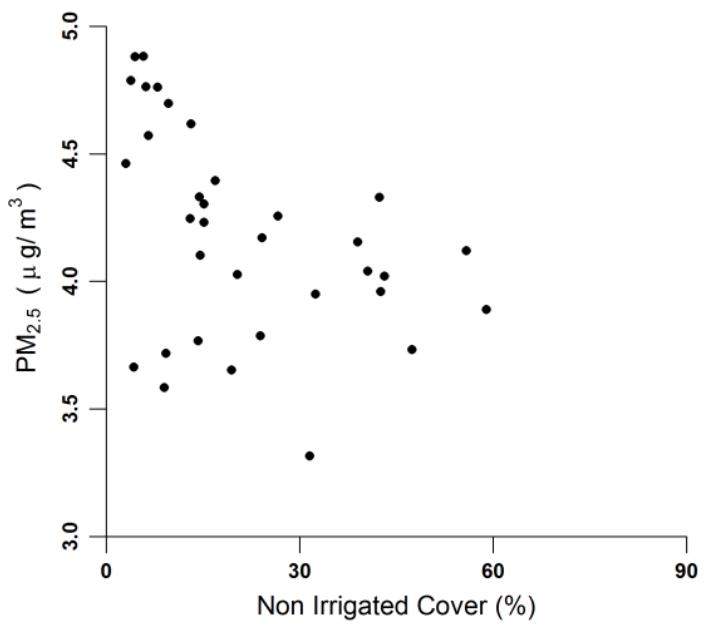

(b) Annual PM 2.5 and Household Poverty
Salt Lake County Zip Code

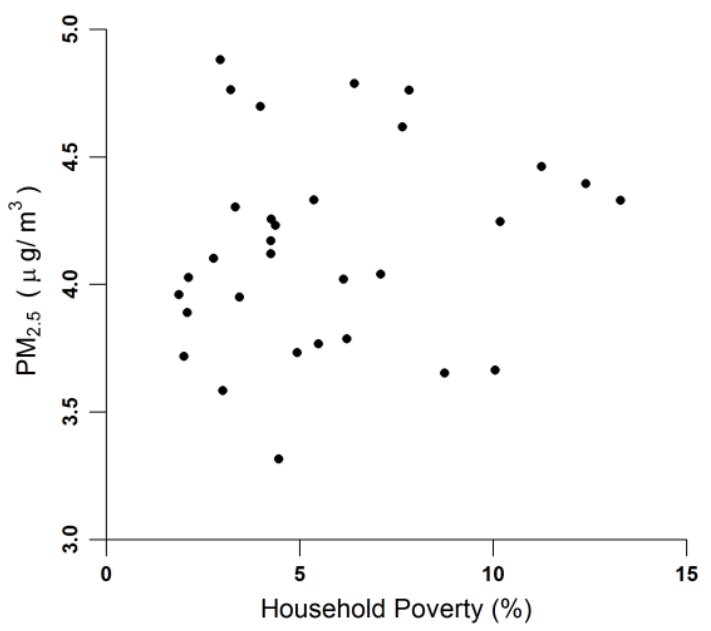

(d)

Figure 3. Annual mean $\mathrm{PM}_{2.5}$ concentration and land cover types and sociodemographic variables at the zip code level: (a) Built cover; (b) Non irrigated cover; (c) Tree cover; and (d) Percent of households living below the poverty line.

\section{Discussion}

The geographical distribution of land cover in Salt Lake County shown in Figure 1 demonstrates the natural and built environment. The Jordan River is the major body of water and runs North-South in the center of the county. The East Side of the county is more mature and composed of more green spaces, including parks, and thus has had more time to develop urban forests. The built and irrigated areas are centrally located because that is where commercial and institutional buildings are found. The irrigated areas correspond to lawns and low shrubs, commonly associated with commercial and some residential buildings.

The relationships between land cover and sociodemographic variables shown in Figure 1 demonstrate a well-established and known pattern that links wealthier and lower minority areas with larger amounts of green space. Conversely, lower income and higher minority areas generally have a higher fraction of its surface as built cover. A visual representation of the East-West divide is shown in Appendix A, Figure A1. 
Localized air pollution is generally most strongly linked to nearby emission sources compared to transport from outside sources. The built environment is associated with both mobile (vehicle) and stationary (buildings, industrial, etc.) sources. Therefore, the relationship between increased pollution and increased built cover is to be expected. Non irrigated cover refers to untouched land cover and is inversely proportional to built cover, thus showing the opposite pattern. Tree cover is either urban forest or undisturbed natural forest. The urban forests are generally located in areas that have higher pollution due to being in more built up areas while undisturbed forests tend to be on the edges of cities and would be associated with less pollution. Elevated periods of $\mathrm{PM}_{2.5}$ are generally found in the winter when most trees are generally inactive thus reducing their ability to filter pollutants. However, with increased incidences of wildfires, particularly in the summer, vegetation may prove to be a more important factor in ameliorating air quality concerns. Finally, while the relationship is less obvious, deeply impoverished areas may be more impacted by higher levels of pollution.

\section{Conclusions}

This study used $1 \mathrm{~m}$ resolved LIDAR data to characterize land use in Salt Lake County, Utah and associate it with sociodemographic and air quality data. This highly resolved data product allowed comparisons at the census block group and zip code level. We found that increasing tree cover was associated with higher per capita income and lower minority populations while increasing built cover was linked to lower per capita income and higher minority populations. Air quality showed less strong correlations, however, decreased non irrigated cover, increased built cover, and higher amounts of households living under poverty was related to higher long-term $\mathrm{PM}_{2.5}$ exposure.

Several positive advances in air quality monitoring and legislative efforts have already taken place in Utah. The TRAX Light-Rail Train Air Quality Observation Project [34] has been monitoring air quality across Salt Lake County since 2015 providing unprecedented spatial and temporal resolution. Air quality data from this project was used in a recent study associating air pollution with school absences [37]. These finding resulted in the 2019 Utah State Legislature passing Rep. Wheatley's HB 0344 "Student Asthma Relief Amendments" [38] which provides stock inhalers (albuterol) to all schools in the state. Based on research showing how the local mass transit system is a valuable tool in reducing air pollutants [39] Rep. Briscoe successfully passed HB 0353 “Reduction of Single Occupancy Vehicle Trips Pilot Program" providing free transit fares on poor air quality days to encourage ridership [40]. Additionally, in an effort to better quantify the environmental impacts of new developments, Sen. Luz Escamilla passed SB 0112 "Inland Port Amendments" [41].

Future work will increase the resolution of air quality observations - both temporally (seasonally) and spatially (census block group level). The health impacts of poor air quality have been well-studied, both in Salt Lake County and elsewhere, however, the link between urban form and health need further development. Finally, our local Planning Agency, the Wasatch Front Regional Council has produced projected land use scenarios [42] and these will be analyzed to understand implications for environmental justice as well as potential air quality and health impacts.

Funding: This research received no external funding.

Acknowledgments: Dr. Phil Dennison, Department of Geography, University of Utah.

Conflicts of Interest: The author declares no conflict of interest.

\section{Appendix A}

The geographical land cover layout of Salt Lake County can be observed in Figure A1. The East Side of the county, to the left of the dividing black line, is more mature and has a higher fraction of green areas, while the West Side of the county, to the right of the dividing black line, is developing quickly and has less green areas due to a higher fraction of industrial and commercial buildings. The downtown area (red oval) is highly built up and has few green areas outside of two parks. 
Figure A1. Southwest-facing view of Salt Lake County. The red oval shows the downtown area and the black line aligns with U.S. Interstate 15 separating the East Side (left) from the West Side (right).

\section{References}

1. Yan, W. Y.; Shaker, A.; El-Ashmawy, N., Urban land cover classification using airborne LiDAR data: A review. Remote Sensing of Environment 2015, 158, 295-310.

2. Wang, K.; Wang, T.; Liu, X., A review: Individual tree species classification using integrated airborne LiDAR and optical imagery with a focus on the urban environment. Forests 2019, 10 (1), 1.

3. Crane, R., The influence of urban form on travel: an interpretive review. Journal of Planning literature 2000, 15 (1), 3-23.

4. Larsen, K.; Gilliland, J.; Hess, P.; Tucker, P.; Irwin, J.; He, M., The influence of the physical environment and sociodemographic characteristics on children's mode of travel to and from school. American Journal of Public Health 2009, 99 (3), 520-526.

5. Nowak, D. J.; Hirabayashi, S.; Bodine, A.; Greenfield, E., Tree and forest effects on air quality and human health in the United States. Environmental pollution 2014, 193, 119-129.

6. Tsai, W.-L.; Leung, Y.-F.; McHale, M. R.; Floyd, M. F.; Reich, B. J., Relationships between urban green land cover and human health at different spatial resolutions. Urban Ecosystems 2019, 22 (2), 315-324.

7. Carpio, O.; Fath, B., Assessing the environmental impacts of urban growth using land use/land cover, water quality and health indicators: A case study of Arequipa, Peru. American Journal of Environmental Sciences 2011, 7 (2), 90-101.

8. Gurney, K. R.; Romero-Lankao, P.; Seto, K. C.; Hutyra, L. R.; Duren, R.; Kennedy, C.; Grimm, N. B.; Ehleringer, J. R.; Marcotullio, P.; Hughes, S., Climate change: Track urban emissions on a human scale. Nature 2015, 525 (7568), 179. 
9. Parshall, L.; Gurney, K.; Hammer, S. A.; Mendoza, D.; Zhou, Y.; Geethakumar, S., Modeling energy consumption and $\mathrm{CO}_{2}$ emissions at the urban scale: Methodological challenges and insights from the United States. Energy Policy 2009, 38 (9), 4765-4782.

10. Markakis, K.; Poupkou, A.; Melas, D.; Tzoumaka, P.; Petrakakis, M., A Computational Approach Based on GIS Technology for the Development of an Anthropogenic Emission Inventory of Gaseous Pollutants in Greece. Water Air and Soil Pollution 2010, 207 (1-4), 157-180.

11. Asefi-Najafabady, S.; Rayner, P. J.; Gurney, K. R.; McRobert, A.; Song, Y.; Coltin, K.; Huang, J.; Elvidge, C.; Baugh, K., A multiyear, global gridded fossil fuel $\mathrm{CO}_{2}$ emission data product: Evaluation and analysis of results. Journal of Geophysical Research: Atmospheres 2014, 119 (17), 10,213-10,231.

12. Hutyra, L. R.; Duren, R.; Gurney, K. R.; Grimm, N.; Kort, E. A.; Larson, E.; Shrestha, G., Urbanization and the carbon cycle: Current capabilities and research outlook from the natural sciences perspective. Earth's Future 2014, 2 (10), 473-495.

13. Avelar, S.; Zah, R.; Tavares-Corrêa, C., Linking socioeconomic classes and land cover data in Lima, Peru: Assessment through the application of remote sensing and GIS. International Journal of Applied Earth Observation and Geoinformation 2009, 11 (1), 27-37.

14. Becker, D. A.; Browning, M. H.; Kuo, M.; Van Den Eeden, S. K., Is green land cover associated with less health care spending? Promising findings from county-level Medicare spending in the continental United States. Urban Forestry \& Urban Greening 2019, 41, 39-47.

15. Lenormand, M.; Louail, T.; Cantú-Ros, O. G.; Picornell, M.; Herranz, R.; Arias, J. M.; Barthelemy, M.; San Miguel, M.; Ramasco, J. J., Influence of sociodemographic characteristics on human mobility. Scientific reports 2015, 5, 10075.

16. Mitchell, B. C.; Chakraborty, J., Landscapes of thermal inequity: disproportionate exposure to urban heat in the three largest US cities. Environmental Research Letters 2015, 10 (11), 115005.

17. Rosenthal, J. K.; Kinney, P. L.; Metzger, K. B., Intra-urban vulnerability to heat-related mortality in New York City, 1997-2006. Health E place 2014, 30, 45-60.

18. Wong, K. V.; Paddon, A.; Jimenez, A., Review of world urban heat islands: Many linked to increased mortality. Journal of Energy Resources Technology 2013, 135 (2).

19. Schinasi, L. H.; Benmarhnia, T.; De Roos, A. J., Modification of the association between high ambient temperature and health by urban microclimate indicators: A systematic review and meta-analysis. Environmental research 2018, 161, 168-180.

20. Rodríguez, M. C.; Dupont-Courtade, L.; Oueslati, W., Air pollution and urban structure linkages: Evidence from European cities. Renewable and Sustainable Energy Reviews 2016, 53, 1-9.

21. Lo, C.; Quattrochi, D. A., Land-use and land-cover change, urban heat island phenomenon, and health implications. Photogrammetric Engineering E Remote Sensing 2003, 69 (9), 1053-1063.

22. Alcock, I.; White, M.; Cherrie, M.; Wheeler, B.; Taylor, J.; McInnes, R.; im Kampe, E. O.; Vardoulakis, S.; Sarran, C.; Soyiri, I., Land cover and air pollution are associated with asthma hospitalisations: A cross-sectional study. Environment international 2017, 109, 29-41.

23. Rouse Jr, J. W.; Haas, R.; Schell, J.; Deering, D., Monitoring vegetation systems in the Great Plains with ERTS. NASA special publication 1974, 351, 309.

24. Motohka, T.; Nasahara, K. N.; Oguma, H.; Tsuchida, S., Applicability of green-red vegetation index for remote sensing of vegetation phenology. Remote Sensing 2010, 2 (10), 2369-2387.

25. Tucker, C. J., Red and photographic infrared linear combinations for monitoring vegetation. Remote sensing of Environment 1979, 8 (2), 127-150. 
26. Breiman, L., Random forests. Machine learning 2001, 45 (1), 5-32.

27. Congalton, R. G., A review of assessing the accuracy of classifications of remotely sensed data. Remote sensing of environment 1991, 37 (1), 35-46. 28. Healthy Salt Lake, 2020 Demographics. Accessed June 5, 2020, Retrieved from http://www.healthysaltlake.org/demographicdata, 2020.

29. American Community Survey ACS, U.S. Census Bureau, Tables B08301, B08135, B19013; 2017.

30. Bares, R.; Lin, J. C.; Hoch, S. W.; Baasandorj, M.; Mendoza, D. L.; Fasoli, B.; Mitchell, L.; Catharine, D.; Stephens, B. B., The Wintertime Covariation of $\mathrm{CO}_{2}$ and Criteria Pollutants in an Urban Valley of the Western United States. Journal of Geophysical Research: Atmospheres 2018, 123 (5), 2684-2703. concentrations in the vicinity of the Great Salt Lake. Atmospheric Science Letters 2016, 17 (9), 480-486.

252 32. Lareau, N. P.; Crosman, E.; Whiteman, C. D.; Horel, J. D.; Hoch, S. W.; Brown, W. O. J.; Horst, T. W., The Persistent Cold-Air Pool Study. Bulletin of the American Meteorological Society 2013, 94 (1), 51-63. Ehleringer, J. R.; Lin, J. C., Monitoring of greenhouse gases and pollutants across an urban area using a light-rail public transit platform. Atmospheric Environment 2018, 187, 9-23.

34. Mendoza, D. L.; Crosman, E. T.; Mitchell, L. E.; Jacques, A.; Fasoli, B.; Park, A. M.; Lin, J. C.; Horel, J., The TRAX Light-Rail Train Air Quality Observation Project. Urban Sci 2019, 3 (4), 108. 35. Pirozzi, C. S.; Jones, B. E.; VanDerslice, J. A.; Zhang, Y.; Paine III, R.; Dean, N. C., Short-Term Air Pollution and Incident Pneumonia. A Case-Crossover Study. Annals of the American Thoracic Society 2018, 15 (4), $449-459$. 36. Setianto, A.; Triandini, T., Comparison of kriging and inverse distance weighted (IDW) interpolation methods in lineament extraction and analysis. Journal of Applied Geology 2013, 5 (1). 37. Mendoza, D. L.; Pirozzi, C. S.; Crosman, E. T.; Liou, T. G.; Zhang, Y.; Cleeves, J. J.; Bannister, S. C.; Anderegg, W. R. L.; Paine III, R., Absentee and Economic Impact of Low-Level Fine Particulate Matter and Ozone Exposure in K-12 Students [Preprint] 2020.

38. Wheatley, M., HB

0344: $\quad$ Student

Asthma Relief

Amendments

267 https://le.utah.gov/ 2019/bills/static/HB0344.html. 2019.

268 39. Mendoza, D. L.; Buchert, M. P.; Lin, J. C., Modeling net effects of transit operations on vehicle miles 269 traveled, fuel consumption, carbon dioxide, and criteria air pollutant emissions in a mid-size US metro area: 270 findings from Salt Lake City, UT. Environmental Research Communications 2019, 1 (9), 091002.

271 40. Briscoe, J., HB 0353: Reduction of Single Occupancy Vehicle Trips Pilot Program 272 https://le.utah.gov/ 2019/bills/static/HB0353.html. 2019.

273 41. Escamilla, L., SB 0112: Inland Port Amendments https://le.utah.gov/ 2020/bills/static/SB0112.html. 2019.

274 42. Wasatch Front Regional Council Regional Transportation Plan 2015-2040; 2015. 